\title{
LMA Observation of Upward Bipolar Lightning Flash at the Säntis Tower
}

\author{
A. Sunjerga ${ }^{1}$, M. Rubinstein ${ }^{2}$, A. Mostajabi ${ }^{1}$, M. Azadifar ${ }^{2}$, N. Pineda ${ }^{3,4}$, D. Romero ${ }^{4}$, O. Van der Velde ${ }^{4}$, \\ J. Montanya ${ }^{4}$, G. Diendorfer ${ }^{5}$, J. Figueras i Ventura ${ }^{6}$, N. Besic ${ }^{6}$, J. Grazioli ${ }^{6}$, A. Hering ${ }^{6}$, U. Germann ${ }^{6}$, \\ F. Rachidi ${ }^{1}$
}

1 Electromagnetic Compatibility Laboratory, Swiss Federal Institute of Technology (EPFL), 1015 Lausanne, Switzerland 2 University of Applied Sciences of Western Switzerland (HES-SO), 1400 Yverdon-les-Bains, Switzerland

3. Meteorological Service of Catalonia, Carrer Berlín 38-46, Barcelona 08029, Spain

4 Lightning Research Group, Technical University of Catalonia, Edifici TR1, Carrer Colom 1, Terrassa 08222, Spain

5 OVE Service GmbH, Dept. ALDIS (Austrian Lightning Detection \& Information System), Vienna, Austria 6 MeteoSwiss, Locarno, Switzerland

\begin{abstract}
We present in this paper lightning current measurements and LMA (Lightning Mapping Array) data associated with an upward bipolar flash observed at the Säntis Tower during the Summer of 2017. The polarity of the flash reversed during the negative initial continuous current phase by a positive pulse. The positive pulse was followed by two negative strokes. The positive pulse was presumably initiated in the lower positive region of the cloud where the positive end of a floating bidirectional leader connected to the lightning channel.
\end{abstract}

Keywords-bipolar flash, leader polarity, mechanism, LMA, lightning mapping array, current, upward, radar

\section{INTRODUCTION}

Bipolar flashes are characterized by a polarity change in the transferred charge to the ground within the same flash. The first reported bipolar event was recorded by McEachron [1] at the Empire State Building, in New York City. Rakov [2] classified bipolar flashes into three categories depending on the signature of the recorded current at the channel base. In the first category, a polarity reversal occurs during the initial continuous current; the second category comprises flashes in which the initial stage current and the following return stroke(s) have different polarities; the third category comprises flashes with return strokes of opposite polarity. Recently, Azadifar et al. [3] reported two bipolar flashes observed at the Säntis tower which were characterized by a sequence of two upward leaders of opposite polarity within the same flash, a scenario that was not reported in previous observations. They suggested a modification of the bipolar flash classification to distinguish between two types of Category I flashes.

The types of cloud structures and discharge processes involved in the formation of bipolar flashes are still not completely understood, even though some scenarios have been suggested in the literature to explain polarity reversal in upward bipolar (e.g., [4,5]) and downward bipolar (e.g., [6,7]) flashes.

In the case of downward bipolar flashes, most of the reported events start with a positive leader. According to [6,7], a positive leader originates from the middle part of the cloud and propagates in a bidirectional manner [8], namely a negative

This work was supported in part by the Swiss National Science Foundation (Project No. 200020_175594), the European Union's Horizon 2020 research and innovation program under grant agreement No 737033-LLR, the Spanish Ministry of Economy and the European Regional Development Fund (FEDER) ESP2015-69909-C5-5-R and ESP2017-86263-C4-2-R, and European Union's Horizon 2020 research and innovation programme under the Marie Skłodowska-Curie grant agreement SAINT 722337. leader upward and a positive leader downward with horizontal branches in the negative charge region. After the occurrence of the return stroke, the positive leader starts to decay and it cuts off from the ground. During that period, recoil leaders are initiated from decayed horizontal branches, initiating negative dart leader processes propagating along the same vertical path of the initial positive leader to the ground and giving rise to negative return strokes.

For upward lightning, Narita et al. [4] suggested that currents of both polarities follow the same channel to the ground, but from different, oppositely charged regions. Further, they assume that different types of bipolar flashes can be observed for the case of the normal and the inverted charge structure. More recently, Shi et al. [5] observed bipolar flashes that exhibited upward positive leader branching in the main negative region; after the cut off from the ground termination, one of the branches propagates to the upper main positive charge changing the polarity of the leader to negative and transferring positive charge to ground.

Downward bipolar lightning appears to be rare, while the statistics for upward bipolar flashes initiated from tall objects range anywhere between $3 \%$ to $33 \%[9,10]$. High occurrence (33\%) of bipolar flashes was observed for winter lightning in Japan [2]. To the best of our knowledge, the reasons for higher occurrence of bipolar flashes to tall structures have not been discussed. One reason might be related to the fact that tall structures can initiate an appreciable number of upward flashes. Bipolar lightning requires a change in the polarity of the fields and the lower field strength needed for tall structures to initiate lightning may mean that the conditions leading to a leader polarity reversal could be achieved with a higher probability in the presence of tall structures.

The aim of this paper is to present simultaneous measurements of current, VHF sources and radar data associated with an upward bipolar flash initiated from the Säntis tower.

The rest of the paper is organized as follows. Section II presents the measurement setup. Section III presents an analysis of the bipolar flash. Final conclusions are given in Section IV. 


\section{MEASUREMENT SETUP}

The 124-m tall Säntis Tower (47 $14^{\prime} 57^{\prime} ' \mathrm{~N}$ and $9^{\circ} 20^{\prime} 32^{\prime}$ 'E) is by far the most frequently struck structure in Switzerland [11]. The tower has been instrumented for current measurements since May 2010 [11-13]. The Säntis area is covered by the EUCLID lightning location network [14]. A Lightning Mapping Array (LMA) based on the Time of Arrival (ToA) method was installed in the Säntis area during the Summer of 2017. The locations of the 6 LMA stations, ranging from $100 \mathrm{~m}$ to $11 \mathrm{~km}$ from the tower, are shown with red markers in Fig. 1 in the local East North Up (ENU) coordinate system, with the origin at the location of the Säntis Tower. The area is also covered by the MeteoSwiss C-band, Doppler polarimetric weather radar network $[15,16]$. For the measurement campaign, data from the Albis radar located near the city of Zurich (shown with the blue marker in Fig. 1) are used. Radar data can be used to categorize the hydrometeor structure of clouds [17] into the following classes: No classification (No valid radar data - NC), dry snow (DS), ice crystals (CR), light rain (LR), rimed particles (RM), rain (RN), vertically-oriented ice crystals (VI), wet snow (WS), melting hail (MH) and ice hail-high density graupel (IH). MeteoSwiss operates a meteorological station near the tower recording wind speed, temperature, pressure and relative humidity. More detailed information on the measuring system can be found in [18].

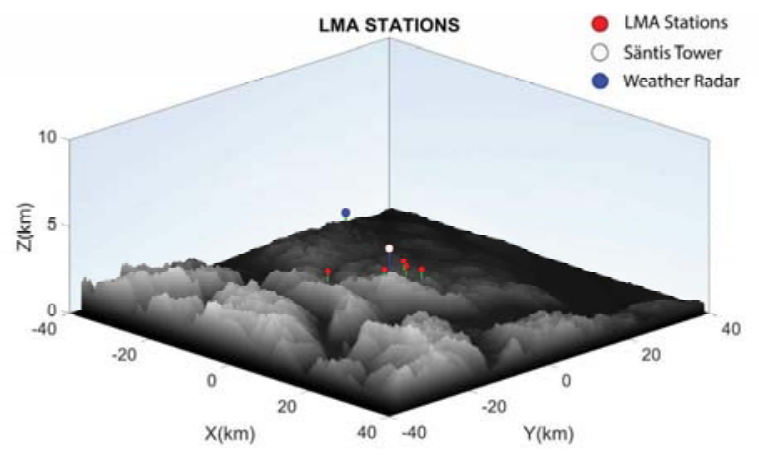

Fig. 1. 5 LMA Stations marked in red around the Säntis area. The 6th station (not shown in the figure) was located in the immediate vicinity of the tower. Weather radar marked with blue and the Säntis Tower in white. Global elevation model from NASA [2015].

\section{BIPOLAR FLASH}

An upward bipolar flash was recorded on July 14, 2017 at 13:25:39 UTC. In what follows, we will analyze the atmospheric conditions, the leader propagation and the measured current at the Säntis Tower associated with this flash.

\section{A. Storm and Cloud Structure}

Figs. 2 and 3 show the reflectivity and cross section classification of hydrometeors [19]. Convective cores crossed the Säntis area from Northwest to Southeast. The convective system that induced the upward leader (UL) from the Tower can be defined as a cluster of cells [20]. We can observe that the melting layer is at about $3 \mathrm{~km}$. The depth of the clouds is relatively low and similar to those observed in Japanese winter storms [5]. Unfortunately, low VHF activity did not allow us to infer the charge structure. We can only hypothesize the structure by knowing the polarity of leaders from current measurements. Prior to this flash, we measured a strong wind $(46.8 \mathrm{~km} / \mathrm{h})$ which possibly caused a more complex charge structure leading to a bipolar discharge.

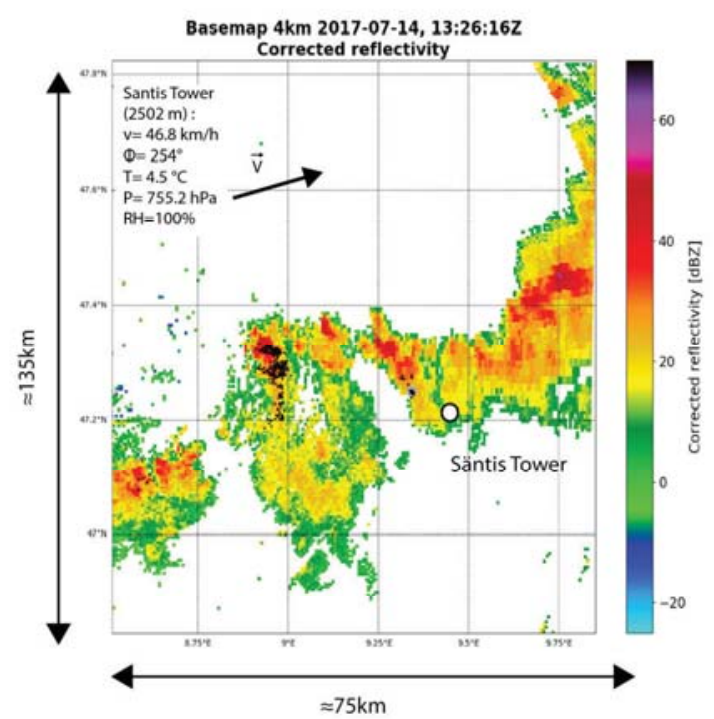

Fig. 2 Radar observations. Top view of the reflectivity. LMA sources are shown with black markers.

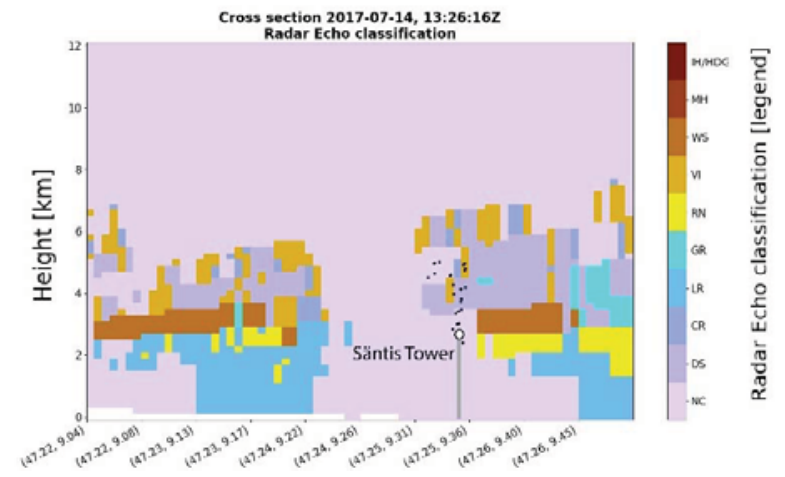

Fig. 3 Radar observations. Hydrometeor classification. LMA sources shown with black markers.

\section{B. Measured Current Waveform}

Fig. 4a. shows the current waveform during the whole flash. Expanded views of different phases are shown in the subplots of Fig. 4b. The flash started with an upward positive leader (ICC phase). Note that the sign of the current in Fig. 4 corresponds to the sign of the charge that is being effectively lowered to the ground. During the still ongoing but decaying ICC, a first positive pulse occurred at about $265 \mathrm{~ms}$. A negative ICC pulse was also recorded at about $266.5 \mathrm{~ms}$, namely about $1.5 \mathrm{~ms}$ after the onset of the positive pulse. The positive pulse indicates the effective lowering of positive charge, either by rising negative change (for instance an upward negative leader), or the lowering of positive charge. Since the positive pulse had a relatively long duration and it did not feature sharp pulses in its rising portion, which are typical of a stepping process, we infer that an upward negative leader was not involved. A change 
of polarity occurred once more during the same flash with two negative subsequent return strokes following the positive pulse. The charge transferred during the ICC was about $-39.3 \mathrm{C}$. The transferred charges during the positive pulse and the two subsequent negative strokes were, respectively, 18.1 C, $-1.13 \mathrm{C}$ and $-1.56 \mathrm{C}$.

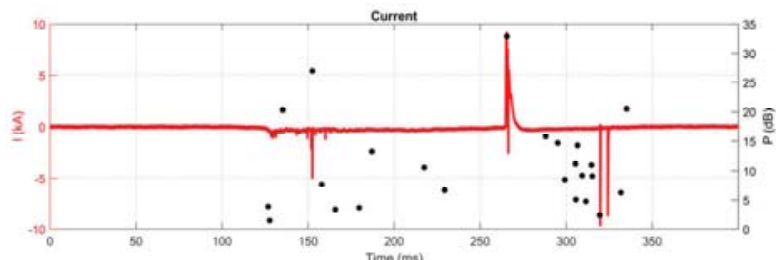

(a)

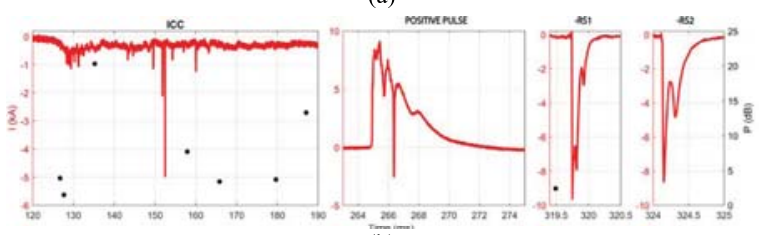

(b)

Fig. 4 (a) Measured current waveform associated with the bipolar flash. (b) Expanded views of the ICC and the three return strokes. VHF sources vs. power on the right $\mathrm{y}$-axis are shown with black markers.

\section{LMA Observations}

Fig. 5 shows simultaneous measurements of current and VHF sources in the local coordinate system of the tower. Unfortunately, during this flash, a very low number of VHF sources were recorded. The flash started with an upward positive leader that was initiated from the tower. The ICC (starting at about $110 \mathrm{~ms}$ in Fig. 5c) lasted for about $150 \mathrm{~ms}$ with VHF sources reaching a height of about $4 \mathrm{~km}$ (see Arrow $\# 1$ in the top left panel of Fig. 5). One ICC pulse at about 152 ms was observed both with VHF source and EUCLID detection. During the decaying phase of the ICC, a positive pulse followed immediately by a faster negative pulse (at about $265 \mathrm{~ms}$ in Fig. 4b and Fig. 5c) were recorded with only one corresponding VHF source located at an altitude of about 2.5 $\mathrm{km}$ (see \#2 in the top panels of Fig. 5). This was followed by some VHF activity, (\#3 in the top panels) prior to the two negative subsequent strokes, and a negative continuous current (CC) period corresponding to the extension of a negative upward leader. The first negative pulse at $265 \mathrm{~ms}$ is in correlation with the floating leader propagating toward the channel (\#3 in the top panels). EUCLID recorded all of the pulses, including an ICC pulse at about $152 \mathrm{~ms}$ and the one which is superimposed on the positive pulse. No VHF or EUCLID sources were recorded 5 minutes prior to the start of the bipolar flash. According to Wang et al. [21], this flash is therefore classified as a 'self-triggered' flash. As can be seen from the middle lower plot (Fig. 5d), the upward leader speed was typical of positive leaders [22].

\section{Sketch of the Process}

Despite the limited number of recorded VHF sources, we will attempt to present a plausible scenario for this bipolar flash, bearing in mind that LMAs have poor resolution for leaders propagating along already ionized channels.
The radar observations show a very shallow cloud structure. From the upward leader propagation and the two negative return strokes, we can infer that negative charges were located at about $3-5 \mathrm{~km}$ height. The positive pulse was initiated from an altitude of about $2.5 \mathrm{~km}$ during the still active ICC current. This flash can therefore be classified as a category I.a flash [23]. It is possible that this originated from the lower positive charge pocket. However, the mechanism of this flash appears to be different from the one reported in [5] even though the cloud structure seems to be similar (shallow clouds with low height above ground). The reversal of polarity appears to be coming from charge deposited in lower parts of the cloud rather than from the upper positive charge region, as was the case in the flash analyzed in [5]. Fig. 6 shows a possible scenario for the evolution of the bipolar flash which comprises the following sequence:

(a) An upward positive leader is initiated from the tower, as can be inferred from the measurement of the initial continuous current.

(b) A floating leader, whose positive end propagates horizontally toward the tower, connects near the bottom of the still conducting channel at about $t \approx 265 \mathrm{~ms}$.

(c) Since no VHF sources associated with the negative pulse superimposed on the positive one were recorded, we assume that this negative pulse was initiated by the connection of a bidirectional leader to the tower tip or the positive channel. The fast negative pulse can be considered to be a mixed-mode ICC pulse since it results from the connection of a new branch to a conducting channel at a low connection height and since it involves the continuous current mode of charge transfer (assuming the slow positive pulse as part of the ICC) and the leader/returns-stroke mode of charge transfer corresponding to the negative pulse itself $[24,25]$. The bidirectional leader might have been initiated in a decayed vertical part of the channel, resulting therefore in negligible VHF emissions. Furthermore, we assume that the change of polarity in the decayed vertical part of the channel occurred through a recoil leader [26] with the positive end propagating upward, and the negative end downward [27].

(d) A negative continuous current is recorded at the channel base suggesting an extension of an upward positive leader.

(e) During the CC period, we observe VHF radiation presumably related to a floating leader close to tip of the upward leader, consistent with the observations reported by Shao et al. [26] in which a dart leader often starts from a point just beyond the far end of a previously active channel. Once the connection is made, a dart leader will travel through the vertical channel reaching the ground and initiating a return stroke. The following return stroke occurred most probably in a similar manner but no VHF sources were detected.

Fig. 6a. also presents the approximate visualization of radar data. The tip of the tower is at the boundary between the rain and dry snow layers. The main channel propagates through dry snow and wet snow in the upper layers. The floating leader causing the positive pulse is apparently located in the dry snow region. 

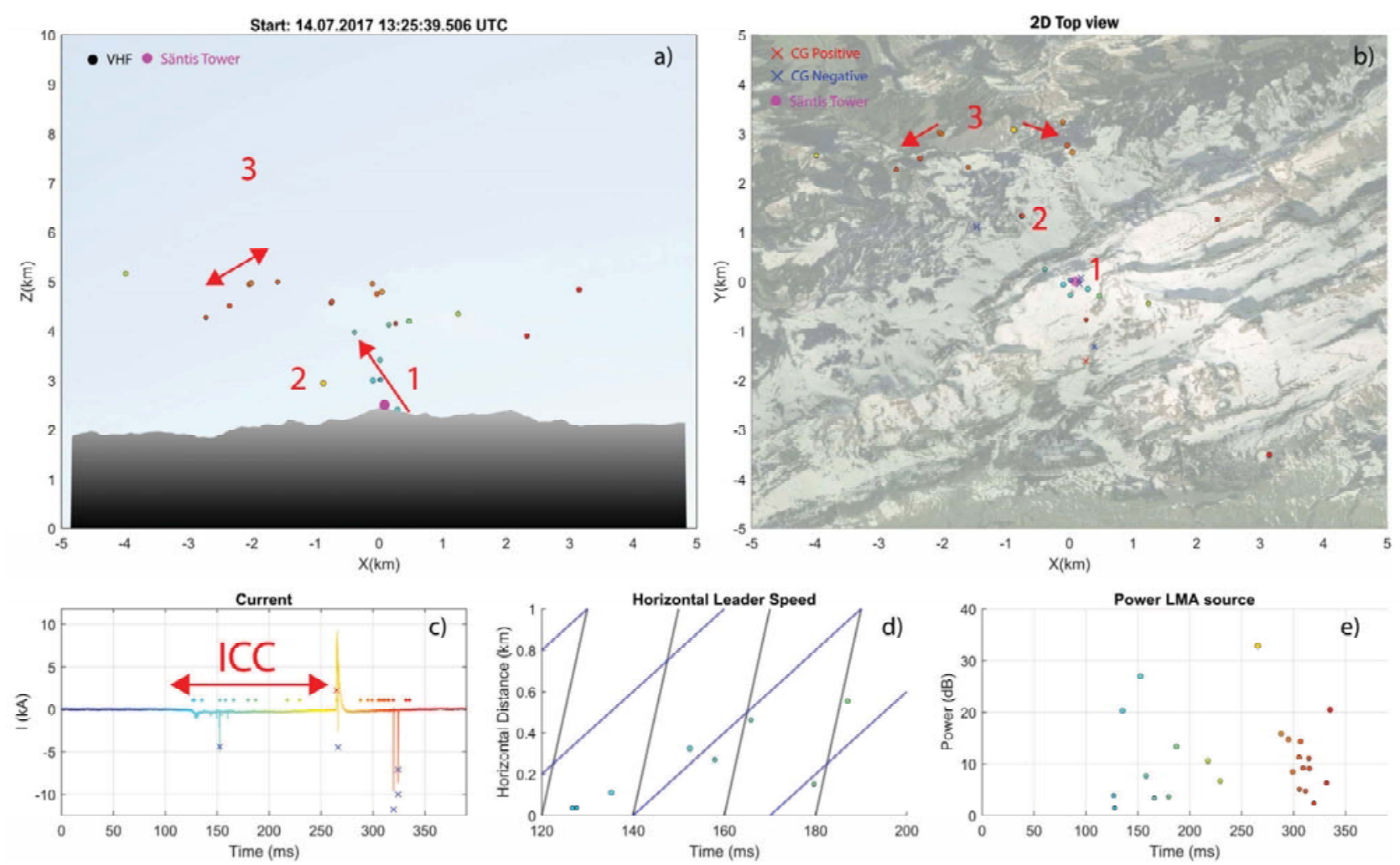

Figure 5. Upward positive flash initiated from the Säntis tower recorded at 29.06.2017 13:38:27 UTC. Measured current and VHF sources in local ENU (East North $\mathrm{Up}$ ) coordinate system with Säntis Tower in origin of $\mathrm{x}-\mathrm{y}$ plane. Location of the tower is shown with purple marker. EUCLID sources are shown with red (positive pulse) and blue (negative pulse) cross. LMA VHF sources are shown with time-coded circle markers. (a) $2 \mathrm{D}$ view $\mathrm{Z}$ vs. Y in top left panel, (b) $2 \mathrm{D}$ view of $\mathrm{X}$ vs. Y in top left panel, (c) current with VHF sources superimposed, (d) horizontal distance vs. time for the case of preceding leader and (e) power vs. time for VHF sources.
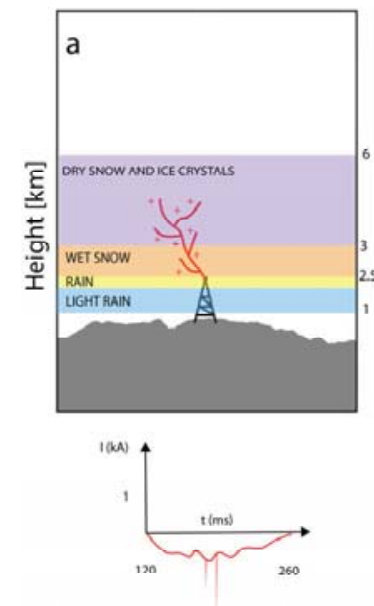
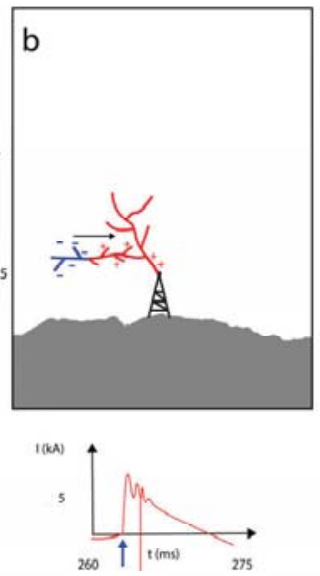
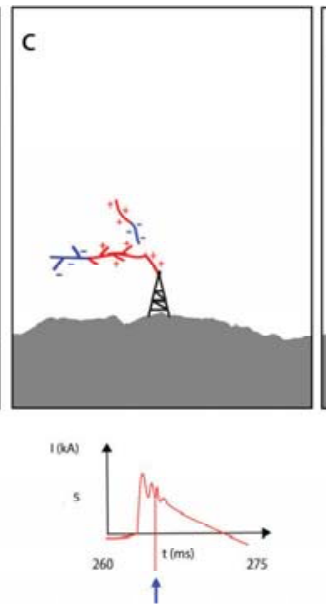
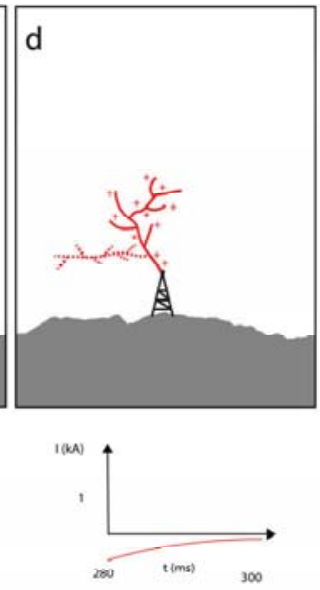
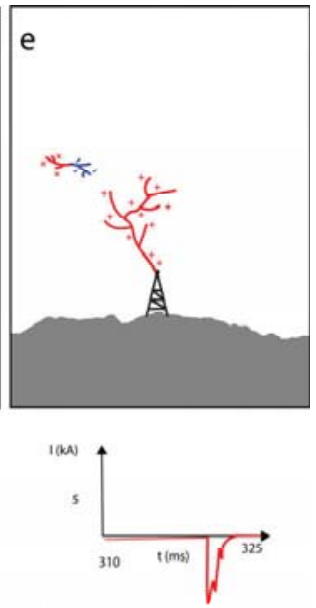

Figure 6. Proposed sketch for evolution of the bipolar flash. (a) upward leader, (b) positive pulse, (c) negative pulse quasi-superimposed on positive, (d) extension of upward positive leader and (e) negative return stroke. The figure is not to scale. The height of the tower is increased for the purpose of illustration. The tip of the tower represents the altitude of Säntis Tower. 
Mazur et al. [24] argued that the TOA lightning mapping technique does not allow simultaneous processing of both, their strong radiation signals from negative breakdowns and the much weaker radiation signals from positive breakdowns. It is not clear for any of the floating leaders if they occurred in a bidirectional or a unidirectional manner. In sequences $\mathrm{b}$ and $\mathrm{c}$, we assumed that a horizontal positive leader occurred in a bidirectional manner with the positive end approaching the original channel. To our knowledge, a bidirectional leader with the positive end developing toward the main vertical channel has not yet been directly observed. The low number of recorded VHF sources prevents us from drawing definitive conclusions.

\section{CONCLUSION}

We have presented and discussed simultaneous measurements of the channel-base current, LMA VHF sources and weather radar observations associated with an upward bipolar flash initiated from the Säntis Tower. The bipolar flash occurred during a low LMA activity period and with no EUCLID sources during the 5 minutes prior to it. The cloud was characterized by a shallow depth. The flash started with a negative ICC and a reversal of polarity occurred twice during the flash. First with a positive pulse, and then with two negative subsequent return strokes. It appears that the upward positive flash (ICC phase) propagated toward the negative charge region. The positive pulse was presumably initiated by the lower positive region of the cloud where the positive end of a floating bidirectional leader connected to a decayed channel.

\section{REFERENCES}

[1] K. B. McEachron, "Lightning to the empire state building," Journal of the Franklin Institute, vol. 227, no. 2, pp. 149-217, Feb. 1939.J. Clerk Maxwell, A Treatise on Electricity and Magnetism, 3rd ed., vol. 2. Oxford: Clarendon, 1892, pp.68-73.

[2] V. A. Rakov, "A Review of Positive and Bipolar Lightning Discharges," Bulletin of the American Meteorological Society, vol. 84, no. 6, pp. 767776, Jun. 2003.K. Elissa, "Title of paper if known," unpublished.

[3] M. Azadifar, F. Rachidi, M. Rubinstein, V. A. Rakov, M. Paolone, and D. Pavanello, "Bipolar lightning flashes observed at the Säntis Tower: Do we need to modify the traditional classification?," Journal of Geophysical Research: Atmospheres, vol. 121, no. 23, p. 14,117-14,126, Dec. 2016.

[4] K. Narita, Y. Goto, H. Komuro, and S. Sawada, "Bipolar lightning in winter at Maki, Japan," Journal of Geophysical Research, vol. 94, no. D11, p. 13191, 1989.M. Young, The Technical Writer's Handbook. Mill Valley, CA: University Science, 1989.

[5] D. Shi et al., "Leader Polarity-Reversal Feature and Charge Structure of Three Upward Bipolar Lightning Flashes," Journal of Geophysical Research: Atmospheres, vol. 123, no. 17, pp. 9430-9442, Sep. 2018.

[6] M. M. F. Saba, C. Schumann, T. A. Warner, J. H. Helsdon Jr., W. Schulz, and R. E. Orville, "Bipolar cloud-to-ground lightning flash observations," Journal of Geophysical Research: Atmospheres, vol. 118, no. 19, p. 11,098-11,106, Oct. 2013.

[7] A. C. V. Saraiva et al., "High-speed video and electromagnetic analysis of two natural bipolar cloud-to-ground lightning flashes," Journal of Geophysical Research: Atmospheres, vol. 119, no. 10, pp. 6105-6127, May 2014

[8] H. W. Kasemir, "A contribution to the electrostatic theory of a lightning discharge," Journal of Geophysical Research, vol. 65, no. 7, pp. 1873 1878, Jul. 1960.

[9] V. A. Rakov, "Lightning parameters for engineering applications (keynote speech)," in 2010 Asia-Pacific International Symposium on Electromagnetic Compatibility, 2010.
[10] M. Azadifar, F. Rachidi, M. Rubinstein, V. A. Rakov, M. Paolone, and D. Pavanello, "Bipolar lightning flashes observed at the Säntis Tower: Do we need to modify the traditional classification?," Journal of Geophysical Research: Atmospheres, vol. 121, no. 23, p. 14,117-14,126, Dec. 2016.

[11] C. Romero et al., "A system for the measurements of lightning currents at the Säntis Tower," Electric Power Systems Research, vol. 82, no. 1, pp. 34-43, Jan. 2012.

[12] C. Romero, A. Mediano, A. Rubinstein, F. Rachidi, A. Rubinstein, and M. Paolone, "Measurement of Lightning Currents Using a Combination of Rogowski Coils and B-Dot Sensors," J. Light. Res., vol. 4, pp. 71-77, 2012 .

[13] C. Romero, F. Rachidi, M. Rubinstein, and M. Paolone, "Lightning currents measured on the Säntis Tower: A summary of the results obtained in 2010 and 2011," in 2013 IEEE International Symposium on Electromagnetic Compatibility, 2013, pp. 825-828.

[14] W. Schulz, G. Diendorfer, S. Pedeboy, and D. R. Poelman, "The European lightning location system EUCLID - Part 1: Performance analysis and validation," Nat. Hazards Earth Syst. Sci, vol. 16, pp. 595-605, 2016

[15] U. Germann, Urs \& Boscacci, Marco \& Gabella, Marco \& Sartori, Maurizio. (2015). Peak Performance: Radar design for prediction in the Swiss Alps. Meteorological Technology International. 42-45.

[16] U. Germann, G. Galli, M. Boscacci, and M. Bolliger, "Radar precipitation measurement in a mountainous region," Quarterly Journal of the Royal Meteorological Society, vol. 132, no. 618, pp. 1669-1692, Jul. 2006.

[17] N. Besic, J. Figueras i Ventura, J. Grazioli, M. Gabella, U. Germann, and A. Berne, "Hydrometeor classification through statistical clustering of polarimetric radar measurements: a semi-supervised approach," Atmospheric Measurement Techniques, vol. 9, no. 9, pp. 4425-4445, Sep. 2016.

[18] A. Sunjerga et al. "LMA observations of Upward Lightning Flashes at the Säntis Tower Initiated by Nearby Lightning Activity", submited to ICLP2018 Special Issue of Electric Power Systems Research (EPSR)

[19] N. Pineda et al., "Meteorological Aspects Of Self-Initiated Upward Lightning At The Säntis Tower (Switzerland)", submitted to the Journal of Geophysical Research - Atmospheres

[20] J. D. Duda and W. A. Gallus Jr., "Spring and Summer Midwestern Severe Weather Reports in Supercells Compared to Other Morphologies," Weather and Forecasting, vol. 25, no. 1, pp. 190-206, Feb. 2010.

[21] D. Wang, N. Takagi, T. Watanabe, H. Sakurano, and M. Hashimoto, "Observed characteristics of upward leaders that are initiated from a windmill and its lightning protection tower," Geophysical Research Letters, vol. 35, no. 2, Jan. 2008.

[22] O. A. van der Velde and J. Montanyà, "Asymmetries in bidirectional leader development of lightning flashes," Journal of Geophysical Research: Atmospheres, vol. 118, no. 24, p. 13,504- 13,519, Dec. 2013.

[23] M. Azadifar et al. "Two Possible Scenarios for the Formation of Category 1 Bipolar Lightning Flashes", submited to AsiaPacific International Conference on Lightning, 2019 Hong Kong, China

[24] V. Mazur, L. H. Ruhnke, T. A. Warner, and R. E. Orville "Recoil leader formation and development," Journal of Electrostatics, vol. 71, no. 4, pp. 763-768, Aug. 2013.

[25] H. Zhou, G. Diendorfer, R. Thottappillil, H. Pichler, and M. Mair, "Mixed mode of charge transfer to ground for initial continuous current pulses in upward lightning," in 2011 7th Asia-Pacific International Conference on Lightning, 2011 .

[26] H. Zhou, V. A. Rakov, G. Diendorfer, R. Thottappillil, H. Pichler, and M. Mair, "A study of different modes of charge transfer to ground in upward lightning," Journal of Atmospheric and Solar-Terrestrial Physics, vol. 125-126, pp. 38-49, Apr. 2015.

[27] X. Qie et al., "Bidirectional leader development in a preexisting channel as observed in rocket-triggered lightning flashes," Journal of Geophysical Research: Atmospheres, vol. 122, no. 2, pp. 586-599, Jan. 2017.

[28] X. M. Shao, P. R. Krehbiel, R. J. Thomas, and W. Rison, "Radio interferometric observations of cloud-to-ground lightning phenomena in Florida," Journal of Geophysical Research, vol. 100, no. D2, p. 2749 1995 